\title{
Fetal Alcohol Syndrome and Fatty Acid Ethyl Esters
}

\author{
CYNTHIA F. BEARER, SUSAN GOULD, RENEE EMERSON, PAULA KINNUNEN, AND
}

CYNTHIA S. COOK

\author{
Children's Hospital Oakland Research Institute, Oakland, California 94609 /C.F.B., S.G., R.E.j; Department of \\ Medicine, Washington University, St. Louis, Missouri 63110 [P.K.]; and Department of Growth and \\ Development, University of California, San Francisco, California 94143 [C.S.C.]
}

\begin{abstract}
Fetal alcohol syndrome is the leading known cause of mental retardation. The syndrome, defined as growth retardation, midface hypoplasia, and neurologic dysfunction, represents only part of the spectrum of fetal alcohol effects. The biochemical mechanism of teratogenesis is unknown. In adults, metabolites of ethanol, FAEE, are known to accumulate in major organs. The formation of FAEE is catalyzed by a family of enzymes, FAEE synthases. Our hypothesis is that accumulation of FAEE in the embryo results in fetal alcohol syndrome. We have developed assays for FAEE and FAEE synthase activity using $\mathrm{mg}$ of tissue. Using these assays, we have shown the following: Human placenta, mouse placenta, heart, and liver are active in catalyzing the formation of FAEE. One $h$ after maternal ethanol administration on gestational d 14, mouse placenta and fetuses accumulated significant quantities of FAEE. The fatty acid incorporated into FAEE was tissue dependent. Tissues from pregnant animals given ethanol on gestational d 7 showed persistence of FAEE on gestational d 14. We conclude that: 1 ) human and mouse placentas have significant FAEE synthase activity, 2) mouse heart, liver, placenta, and fetal tissues accumulate significant amounts of FAEE after maternal ethanol exposure, 3) there is tissue specificity for the fatty acid incorporated into FAEE, and 4) FAEE may persist for 7 d in placentas. These results provide a basis for further research into the role of FAEE in the development of fetal alcohol syndrome. (Pediatr Res 31: 492-495, 1992)
\end{abstract}

\section{Abbreviations}

FAS, fetal alcohol syndrome

FAEE, fatty acid ethyl esters

ADH, alcohol dehydrogenase

GST, glutathione S-transferase

FAS was first described in France in 1969 (1) and reached general recognition in 1971 with eight cases in Seattle $(2,3)$. Since then, FAS has been recognized internationally with an incidence of $1-2$ per 1000 live births and has been found to be the leading cause of mental retardation in the United States. A markedly higher incidence has been documented in some populations such as certain American Southwest Indian tribes (4), indicating a potential behavioral or genetic predisposition to FAS.

Received September 9, 1991; accepted December 18, 1991.

Correspondence: Dr. C. F. Bearer, Children's Hospital Oakland, 747 Fifty Second St., Oakland, CA 94609.

Supported by East Bay Neonatology Foundation and by the Association for Retarded Citizens of the United States.
The mechanism of ethanol-induced teratogenesis is unknown, and current hypotheses include altered placental nutrient transport, fetal hypoxia due to umbilical artery constriction and increased oxygen consumption secondary to ethanol, abnormal muscle organogenesis, prostaglandin and fetal cAMP effects, and altered hormone metabolism (5). However, currently available data do not identify the primary site of action for alcohol or any biochemical mechanism of fetal alcohol toxicity.

Ethanol metabolism in mammals occurs primarily in the liver via two different pathways, oxidation of ethanol to acetaldehyde by either ADH or the microsomal ethanol-oxidizing system (6). Nonoxidative metabolism of ethanol to FAEE occurs in both liver and extrahepatic tissues (7) and is catalyzed by FAEE synthases. These lipids have been shown to bind to mitochondria in intact cells and to uncouple oxidative phosphorylation in mitochondrial preparations in vivo (8). Synthesis and accumulation of FAEE in human pancreas, liver, adipose tissue, heart, bone marrow, peripheral leukocytes, cerebral cortex, skeletal muscle, and aorta after ethanol ingestion have been demonstrated and may represent a mechanism for ethanol-induced toxicity in organs lacking ADH (9). Thus, this pathway may play a role in the pathophysiology of alcohol-induced organ damage.

The nonoxidative metabolism of ethanol in fetal and placental tissues has not previously been described. Existing experimental models for FAS include animal models and cell culture systems. In pregnant $\mathrm{C} 57 \mathrm{Bl} / 6 \mathrm{~J}$ mice, ethanol administration on $\mathrm{d} 7$ results in eye abnormalities similar to those seen in humans: ptosis, anterior segment dysgenesis, and optic nerve dysplasia (10). Additionally, in rats fed $35 \%$ of their calories as ethanol, embryonal neural division and migration were affected in the cerebral cortex, and behavioral effects were observed (11). In vitro, ethanol inhibits process formation in CNS sensory neurons and production of neurotrophic factors (12). The biochemical basis for these findings has not been elucidated. ADH is virtually absent in the fetus, and ethanol equilibrates rapidly across the placenta, resulting in exposure of fetal tissue to ethanol levels that have been shown to result in FAEE accumulation in adults (13).

Our hypothesis is that accumulation of FAEE may cause or contribute to the embryopathy of FAS. The current experiments were designed to determine whether nonoxidative ethanol metabolism and FAEE accumulation occur in fetal and placental tissue in the C57BI/6J mouse model of FAS and whether human placenta contains FAEE synthase activity.

\section{MATERIALS AND METHODS}

Tissues. Human placenta obtained within an hour of delivery was minced, washed with ice-cold normal saline, and kept frozen at $-70^{\circ} \mathrm{C}$ until use. Pregnant $\mathrm{C} 57 \mathrm{Bl} / 6 \mathrm{~J}$ mice were given either $0.015 \mathrm{~mL} / \mathrm{g}$ of $4.25 \mathrm{M}(25 \%)$ ethyl alcohol or an equal amount of saline in two doses by intraperitoneal injection $4 \mathrm{~h}$ apart on 
the specified gestational day. Animals were killed $1 \mathrm{~h}$ after the second dose by cervical dislocation, and tissues were dissected and immediately placed in liquid nitrogen. Litters of placentas and fetuses were combined. Tissues were homogenized in icecold $10 \mathrm{mM}$ Tris, $\mathrm{pH} 8.0$, and $1 \mathrm{mM}$ mercaptoethanol with a polytron (Brinkmann Instruments, Westbury, NY) for $30 \mathrm{~s}$.

FAEE synthase was measured as described (14). Tissue homogenate was centrifuged at $200 \times g$ for $5 \mathrm{~min}$. The supernatant was added to an assay mixture such that the final concentrations were $200 \mathrm{mM}$ ethanol, $0.4 \mathrm{mM}{ }^{14} \mathrm{C}$-oleic acid (sp act $6000 \mathrm{cpm} /$ nmol; ICN, Plainview, NY), and $60 \mathrm{mM}$ Tris, $\mathrm{pH}$ 7.5. The mixture was incubated at $37^{\circ} \mathrm{C}$ for $1 \mathrm{~h}$ and quenched on ice. Two $\mathrm{mL}$ of acetone were added, with $5000 \mathrm{cpm}$ of ${ }^{3} \mathrm{H}$-ethyl oleic acid for determination of recovery of ${ }^{14} \mathrm{C}$-labeled product and $600 \mathrm{nmol}$ of ethyl oleate to serve as cold carrier. FAEE were separated from unreacted substrate by chromatography on Anasil 0 plates (Phase Separations, Norwalk, CT) using a petroleum ether:diethyl ether:acetic acid (75:5:1, vol/vol/vol) solvent system. FAEE were visualized with iodine vapor, iodine was removed by gentle heating, and the spots corresponding to FAEE were scraped into scintillation vials. Ten $\mathrm{mL}$ of scintillant was added, and samples were counted on a Beckman counter. Results were corrected for recovery of ${ }^{3} \mathrm{H}$-ethyl oleate and expressed as $\mathrm{nmol}$ of ethyl oleate formed per $\mathrm{h}$ per $\mathrm{mg}$ of protein.

FAEE was quantitated as previously described (15). Briefly, tissue was placed in ice-cold $10 \mathrm{mM}$ Tris buffer, $\mathrm{pH} 8.0,1 \mathrm{mM}$ mercaptoethanol and homogenized. Aliquots of the homogenate were removed for enzyme assay. Ethyl heptadecanoate, a nonphysiologic internal standard, was added for determination of recovery. The homogenate was extracted with acetone and filtered. The acetone extract was evaporated under nitrogen, and run on thin-layer chromatography in petroleum ether:diethyl ether:acetic acid (75:5:1, vol/vol/vol) solvent system. The FAEE fraction was identified by comigration with authentic standards $\left(\mathrm{R}_{\mathrm{f}} \sim 0.5\right)$, scraped, and eluted with acetone. FAEE were identified by retention times within 0.05 min of authentic FAEE standards using gas chromatography (Shimadzu Scientific Instruments, Inc., Columbia, MD) and quantitated by integration of peak areas compared with the peak area of the internal standard, ethyl heptadecanoate. $0.01 \mathrm{nmol}$ of FAEE could be reliably measured.

Protein was assayed by the Bio-Rad protein assay (Bio-Rad Laboratories, Cambridge, MA).

\section{RESULTS}

FAEE synthase in human placenta. Term human placenta contains FAEE synthase activity. As shown in Figure 1, the activity is linear to $0.4 \mathrm{mg}$ of protein. The activity is also linear with time to at least $100 \mathrm{~min}$ and is abolished by boiling for 5 min (Fig. 2). At $\mathrm{pH} \mathrm{7.5,} \mathrm{the} \mathrm{Km}$ for oleic acid is $0.4 \mathrm{mM}$ (Fig.

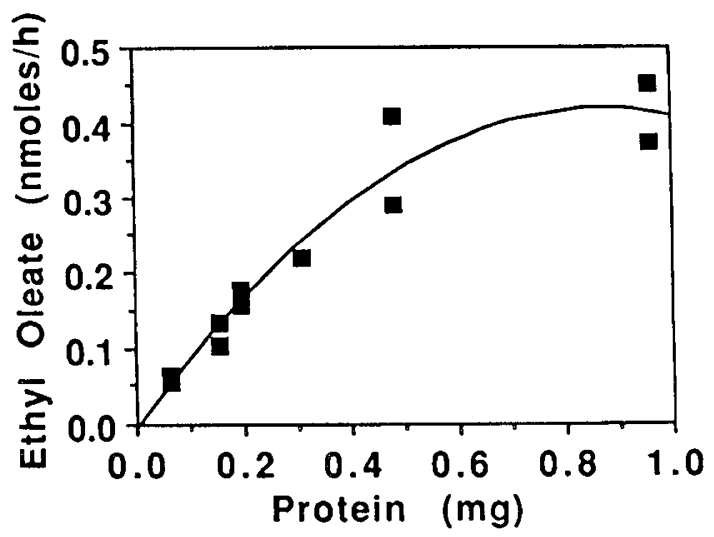

Fig. 1. Human term placenta FAEE synthase activity as a function of protein. Indicated amounts of placental protein were added to reaction mix as described in Materials and Methods. Activity is expressed as nmol of ethyl oleate formed per $h$ per mg protein.

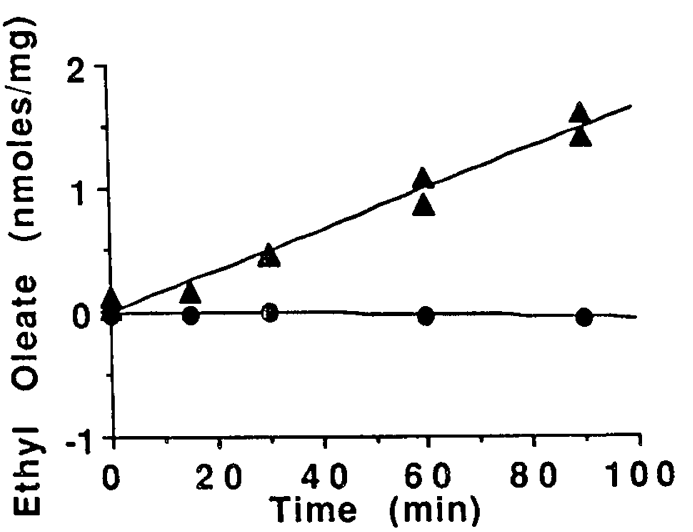

Fig. 2. Human term placenta FAEE synthase activity as a function of time. Placental protein was incubated in the presence of $200 \mathrm{mM}$ ethanol, $0.4 \mathrm{mM}{ }^{14} \mathrm{C}$-oleic acid, and $60 \mathrm{mM}$ Tris, $\mathrm{pH} 7.5$, at $37^{\circ} \mathrm{C}$. At the times indicated, the reaction was quenched on ice, and FAEE were quantitated as described in Materials and Methods.

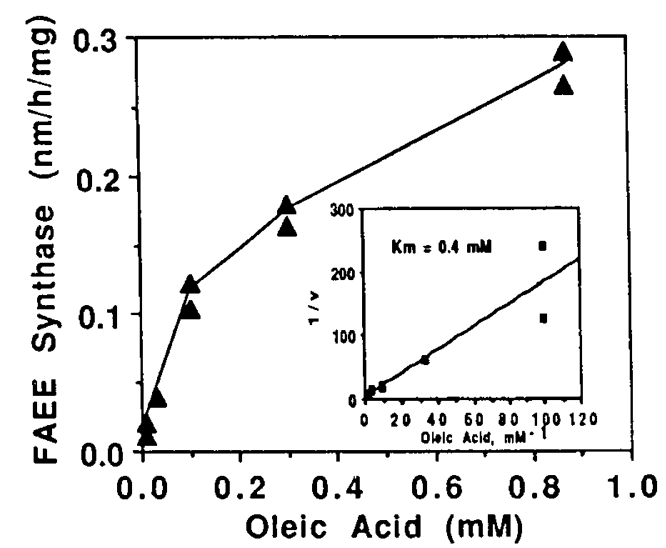

Fig. 3. Human term placenta FAEE synthase activity as a function of oleic acid concentration. Placental protein was incubated in the presence of $200 \mathrm{mM}$ ethanol, $60 \mathrm{mM}$ Tris, $\mathrm{pH} 7.5$, and varying amounts of oleic acid. The assay was performed as described in Materials and Methods. Insert, The data has been replotted in a double reciprocal plot and the $\mathrm{Km}$ has been calculated for oleic acid.

3). In the absence of ethanol, no FAEE are formed (data not shown). These results demonstrate that the FAEE synthase activity of term human placenta is likely to be enzymatic. The $\mathrm{Km}$ of $0.4 \mathrm{mM}$ for oleic acid compares with a $\mathrm{Km}$ of $0.23 \mathrm{mM}$ of the major human myocardium FAEE synthase (16).

FAEE synthase in mouse placenta, heart, and liver. Mouse tissues were also examined for presence of FAEE synthase activity. As shown in Figure 4, gestational d 14 placenta $(1.2 \mathrm{nmol} /$ $\mathrm{h} / \mathrm{mg}$ protein) is as active as maternal heart $(1.1 \mathrm{nmol} / \mathrm{h} / \mathrm{mg}$ protein). In comparison, liver is almost twice as active $(3.9 \mathrm{nmol} /$ $\mathrm{h} / \mathrm{mg}$ protein).

FAEE accumulation in adult, fetal, and placental mouse tissues. $\mathrm{C} 57 \mathrm{Bl} / 6 \mathrm{~J}$ mice were used to study the association of FAEE accumulation and development of FAS. In initial studies, dams were given ethanol or saline as described in Materials and Methods on gestational d 14. FAEE were quantitated in the maternal heart and liver, placentas, and fetuses by acetone extraction, thin-layer chromatography, and gas chromatography. Two representative gas chromatographs of placental FAEE are shown in Figure 5. The placenta of the saline-treated animal shows a complete absence of FAEE, whereas the ethanol-exposed placenta clearly has a new peak corresponding to ethyl stearate. The identity of this lipid as ethyl stearate has been confirmed by gas chromatography-mass spectroscopy (results not shown). FAEE can be quantitated by comparison to the internal standard. 


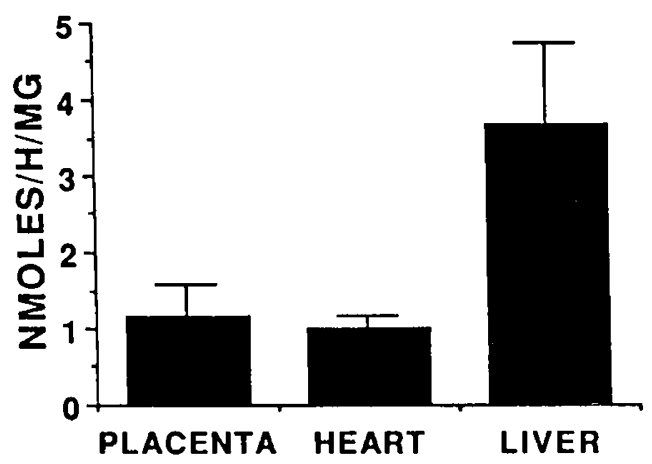

Fig. 4. Mouse placenta, heart, and liver FAEE synthase activity. Tissues were assayed as described in Materials and Methods. Placentas from one litter were pooled before homogenization. Error bars represent the SEM.
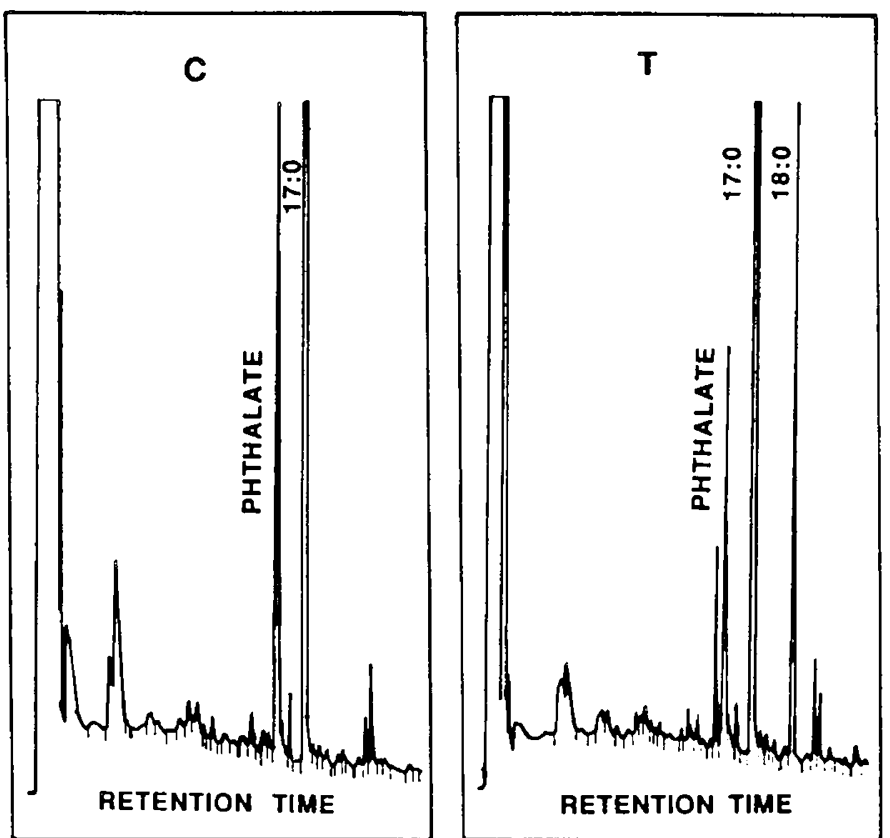

Fig. 5. Gas chromatographs of gestational d 14 mouse placentas. FAEE was extracted as described in Materials and Methods. Panel $C$, FAEE extract from placenta of saline-treated mouse. Panel $T$, FAEE extract from placenta of ethanol treated mouse.

Results from maternal tissues and placentas are shown in Figure 6 . These results show that FAEE accumulates in both maternal tissues and placenta after maternal exposure to ethanol. Of note, the fatty acyl moieties of FAEE are different in the different tissues. Placenta preferentially accumulates ethyl stearate, adult liver accumulates ethyl stearate and ethyl oleate, and heart accumulates ethyl oleate.

Fetal FAEE accumulation is shown in Figure 7. Marked accumulation of FAEE occurs in ethanol-exposed fetal animals (10.9-15.6 nmol total FAEE/g tissue). FAEE of predominantly ethyl palmitate $(2.7-3.7 \mathrm{nmol} / \mathrm{g}$ tissue $)$, ethyl stearate $(4.0-5.5$ $\mathrm{nmol} / \mathrm{g}$ tissue), and ethyl oleate $(2.1-2.7 \mathrm{nmol} / \mathrm{g}$ tissue) could be detected.

$F A E E$ synthase and FAEE in 17 placenta. The presence of FAEE synthase in placenta on gestational d 7 with resultant FAEE accumulation and persistence of FAEE for at least $7 \mathrm{~d}$ was suggested by the following experiment. Dams were treated with ethanol either on gestational $d 7$ only or on $d 7$ and 14 . Animals were killed on $\mathrm{d} 14,2 \mathrm{~h}$ after the last ethanol dose, and tissues were examined for FAEE (Fig. 8). Animals treated on $\mathrm{d} 7$ and 14 showed FAEE accumulation in placenta, heart, and liver comparable to results in Figure 2 . Again, placenta preferentially

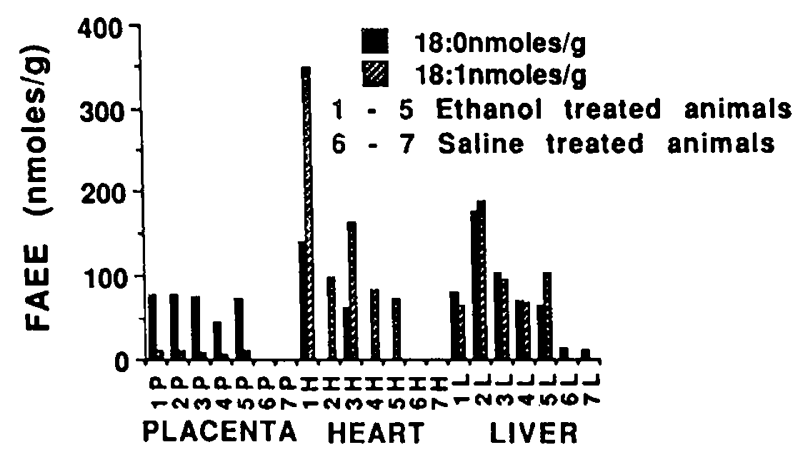

Fig. 6. FAEE accumulation on gestational d $14,1 \mathrm{~h}$ after maternal treatment. FAEE are expressed as nmol of FAEE per $g$ of tissue. Five animals (1-5) were administered ethanol as described in Materials and Methods, and two animals ( 6 and 7) were given saline. The placentas, maternal heart, and liver were isolated, and FAEE was extracted and quantitated.

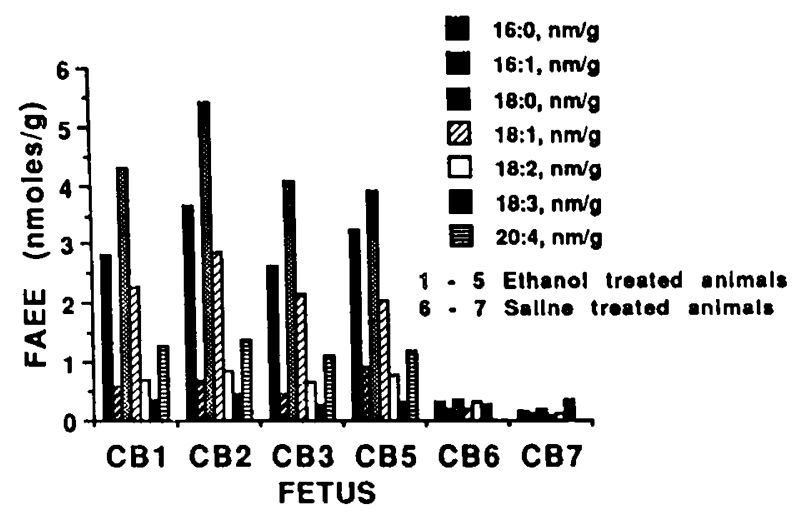

Fig. 7. FAEE accumulation on gestational d 14, $1 \mathrm{~h}$ after maternal treatment. FAEE are expressed as nmol of FAEE per $g$ of tissue. Five animals (1-5) were given ethanol as described in Materials and Methods, and two animals ( 6 and 7$)$ were given saline. The fetuses were removed, and FAEE was extracted and quantitated. The fetuses from animal $C B 4$ were analyzed individually. These results are not shown here.

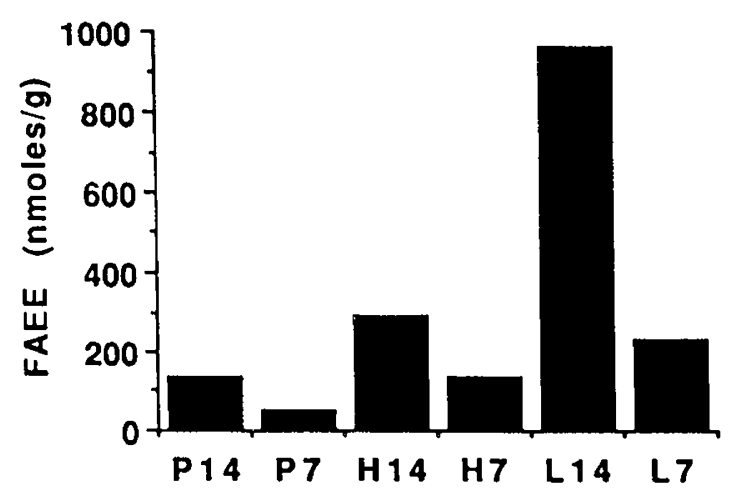

Fig. 8. FAEE accumulation at gestational d 14 after maternal ethanol administration on gestational d $7(P 7, H 7, L 7)$ or gestational $\mathrm{d} 7$ and 14 $(P 14, H 14, L 14)$. FAEE is expressed as nmol of FAEE total per $\mathrm{g}$ of tissue.

accumulated ethyl stearate, whereas heart and liver accumulated ethyl oleate. However, tissues obtained on gestational d 14 from animals treated only on gestational d 7 still had significant quantities of FAEE present. This result suggests the presence of FAEE synthase in 7 placenta with resultant FAEE accumulation. Additionally, the presence of residual FAEE $7 \mathrm{~d}$ after ethanol exposure suggests that FAEE in placenta have a half-life of at least $50-80 \mathrm{~h}$. A half life of $16 \mathrm{~h}$ has been measured in rabbit adipose tissue (17). 


\section{DISCUSSION}

FAS is a global disorder with multiple organ systems affected. In a survey of 248 diagnosed cases of FAS, abnormalities were noted in the CNS, the eyes, the craniofacial structures, the cardiac system, and the genitourinary system. The CNS appears to be particularly sensitive, with effects on intelligence quotient noted with maternal "social drinking" (18) and errors in neuronal and glial migration noted on neuropathologic examinations of children with FAS (19). The ocular malformations occur in almost $90 \%$ of humans with FAS (20), with the most frequently observed malformations being hypoplasia of the optic nerve and retinal vessel tortuosity resulting in decreased visual acuity.

The biochemical basis for these effects remains unknown, despite well-characterized animal models for the development of this syndrome. In the $\mathrm{C} 57 \mathrm{Bl} / 6 \mathrm{~J}$ mouse line, two doses of ethanol result in eye abnormalities consistent with FAS in $50 \%$ of the pups, which span the range seen in humans, including ptosis, microphthalmia, anterior segment dysgenesis, and optic nerve dysplasia $(10,21)$. In rats fed $35 \%$ of their calories as ethanol, both neuronal division and migration in the cerebral cortex were affected in the embyros (11).

Given the virtual lack of ADH in fetal tissues, the short halflife of ethanol in the blood, and the effects observed at low doses of ethanol, a direct effect of ethanol and/or its oxidative metabolites does not seem likely to be the major mechanism for FAS. This study demonstrates for the first time the presence of a nonoxidative metabolite of ethanol in fetal tissues. Specifically, we have shown the accumulation of FAEE in fetal tissue of the C57Bl/6J mouse model of FAS, using doses of ethanol previously shown to result in morphologic abnormalities consistent with FAS. Identification of these lipids may represent a useful marker for FAS, and their accumulation may have a toxic effect on cellular metabolism directly resulting in the developmental abnormalities of FAS.

We also demonstrated the accumulation of these lipids in placenta and maternal heart and liver after ethanol exposure. The tissue specificity of FAEE in these samples may reflect tissue expression of different types of FAEE synthase or different fatty acid substrate pools in each tissue. In addition, the persistence of measurable levels of these lipids for at least $7 \mathrm{~d}$ after exposure is noteworthy. Thus, the effects of alcohol toxicity may be of longer duration than reflected by blood alcohol levels.

Interaction between FAEE and cholesterol metabolism has been previously suggested (7). Interestingly, further interactions have recently been described in Fu5AH rat hepatoma cells (22). The FFA released from FAEE in this cell line are preferentially incorporated into cholesterol esters. These findings suggest further interactions between ethanol and cholesterol metabolism. The existence and significance of these interactions remain to be elucidated in fetal and placenta tissues.

Previous studies have described the copurification of FAEE synthase and GST activities from human heart and the sequence similarities between these two enzymes $(23,24)$. GST is known to be abundant in placenta. The tissue specificity of GST enzymes may be the basis for the tissue specificity of FAEE described here. However, a recent article has failed to confirm the copurification of GST and FAEE synthase activities (25). Therefore, the relationship of FAEE synthases to the GST protein family $(26,27)$ will need further evaluation.

These studies have also identified for the first time FAEE synthase activity in human placenta. We have demonstrated that human placenta synthesizes FAEE with kinetic properties similar to that of the human myocardial enzyme.

We conclude that: 1) human and mouse placentas have significant FAEE synthase activity, 2) mouse heart, liver, placenta, and fetal tissues accumulate significant amounts of FAEE after maternal ethanol exposure, 3 ) there is tissue specificity for the fatty acid incorporated into FAEE, and 4) FAEE may persist for $7 \mathrm{~d}$ in placentas. These results provide a basis for further research into the role of FAEE in the development of FAS.

\section{REFERENCES}

1. Lemoine P, Harousseau H, Borteryu JP, Menuet JC 1968 Les enfants de parents alcoholiques: anomalies observées à propos de 127 cas. Quest Med 21:476-482

2. Jones KL, Smith DW, Ulleland CN, Streissguth P 1973 Pattern of malformation in offspring of chronic alcoholic women. Lancet 1:1267-1271

3. Clarren SK, Smith DW 1978 The fetal alcohol syndrome: medical progress. N Engl J Med 298:1063-1067

4. May PA, Hymbaugh KJ, Aase JM, Samet JM 1983 Epidemiology of fetal alcohol syndrome among American Indians of the Southwest. Soc Biol 30: 374-387

5. Hoyseth KS, Jones P 1989 Ethanol induced teratogenesis: characterization, mechanisms and diagnostic approaches. Life Sci 44:643-649

6. Lieber CS, DeCarli LM 1970 Hepatic microsomal ethanol-oxidizing system. In vitro characteristics and adaptive properties in vivo. $\mathrm{J}$ Biol Chem 245:2505-2512

7. Lange LG 1982 Nonoxidative ethanol metabolism: formation of fatty acid ethyl esters by cholesterol esterase. Proc Natl Acad Sci USA 79:3954-3957

8. Lange LG, Sobel BE 1983 Mitochondrial dysfunction induced by fatty acid ethyl ester, myocardial metabolites of ethanol. J Clin Invest 72:724-731

9. Laposata EA, Lange LG 1986 Presence of nonoxidative ethanol metabolism in human organs commonly damaged by ethanol abuse. Science 231:497499

10. Sulik KK, Johnston MC, Webb MA 1981 Fetal alcohol syndrome: embryogenesis in a mouse model. Science 214:936-938

11. Miller MW 1987 Effect of prenatal exposure to alcohol on the distribution and time of origin of corticospinal neurons in the rat. J Comp Neurol 257:372382

12. Dow KE, Riopelle RJ 1985 Ethanol neurotoxicity: effects on neurite formation and neurotrophic factor reproduction in vitro. Science 228:591-593

13. Pikkarainen PH, Raiha NCR 1967 Development of alcohol dehydrogenase activity in the human liver. Pediatr Res 1:165-168

14. Lange LG, Bergmann SR, Sobel BE 1981 Identification of fatty acid ethyl esters as products of rabbit myocardial ethanol metabolism. J Biol Chem 256:12968-12973

15. Kinnunen PM, Lange LG 1984 Identification and quantitation of fatty acid ethyl esters in biological specimens. Anal Biochem 140:567-576

16. Mogelson S, Lange LG 1984 Nonoxidative ethanol metabolism in rabbit myocardium: purification to homogeneity of fatty acid ethyl ester synthase. Biochemistry 23:4075-4081

17. Laposata EA, Scherner DE, Lange LG 1989 Fatty acid ethyl esters in adipose tissue. Arch Pathol Lab Med 113:762-766

18. Streissguth AP, Barr HM, Sampson PD, Darby BL, Martin DC 1989 IQ at age 4 in relation to maternal alcohol use and smoking during pregnancy. Dev Psychobiol 25:3-11

19. Peiffer J, Majewski F, Fischbach H, Bierich JR, Volk B 1979 Alcohol and fetopathy: neuropathology of 3 children and 3 fetuses. J Neruol Sci 41:125137

20. Stromland K 1987 Ocular involvement in the fetal alcohol syndrome. Surv Ophthalmol 31:277-284

21. Cook CS, Nowotny AZ, Sulik KK 1987 Fetal alcohol syndrome: eye malformations in a mouse model. Arch Ophthalmol 105:1576-1581

23. Bora PS, Spilburg CA, Lange LG 1989 Identification of a satellite fatty acid ethyl ester synthase from human myocardium as a glutathione $S$-transferase. Clin Invest 84:1942-1946

24. Bora PS, Spilburg CA, Lange LG 1989 Metabolism of ethanol and carcinogens by glutathione transferases. Proc Natl Acad Sci USA 86:4470-4473

25. Sharma R, Gupta S, Singhal S, Ahmad H, Haque A, Awasthi Y 1991 Independent segregation of glutathione S-transferase and fatty acid ethyl ester synthase from pancreas and other human tissues. J Biochem 275:507-513

26. Mannervik B, Danielson UH 1988 Glutathione transferases: structure and catalytic activity. CRC Crit Rev Biochem 23:283-337

27. Pickett CB, Lu AYH 1989 Glutathione S-transferases: gene structure, regulation, and biological function. Annu Rev Biochem 58:743-764

28. Laposata EA, Harrison EH, Hedberg EB 1990 Synthesis and degradation of fatty acid ethyl esters by cultured hepatoma cells exposed to ethanol. J Biol Chem 265:9688-9693 